\title{
Clinical study on screw loosening in dental implant prostheses: a 6-year retrospective study
}

\author{
Ki-Young Lee ${ }^{1, \star}$, Kyung Su Shin ${ }^{2, \star}$, Ji-Hye Jung ${ }^{1}$, Hye-Won Cho', Kyung-Hwan Kwon ${ }^{2, \dagger}$, Yu-Lee Kim ${ }^{1, \dagger}$ \\ Departments of ${ }^{1}$ Prosthodontics and ${ }^{2}$ Oral and Maxillofacial Surgery, Wonkwang University Dental Hospital, \\ College of Dentistry, Wonkwang University, Iksan, Korea
}

\begin{abstract}
J Korean Assoc Oral Maxillofac Surg 2020;46:133-142)
Objectives: In this study, we determined the incidence and pattern of screw loosening in patients who received dental implants.

Materials and Methods: Patients who received implants between January 2008 and October 2013 and completed their prosthetic rehabilitation were evaluated for the incidence, frequency, and onset of screw loosening using dental charts and radiographs. The association between each factor and screw loosening was analyzed using the chi-square test and a multivariate analysis with binary logistic regression models $(P<0.05)$.

Results: Total 1,928 implants were placed in 837 patients (448 males, 389 females), whose follow-up period after loading varied from 0.25 to 70 months (mean period, 31.5 months). Screw loosening occurred in $7.2 \%$ of implants. Most cases occurred less than six months after loading. Among those, $22.3 \%$ experienced recurrent screw loosening. Screw loosening was most common in the molar region ( $8.5 \%)$ and frequently associated with an implant diameter of $\geq 5 \mathrm{~mm}(14.2 \%)$. External implant-abutment connections $(8.9 \%)$ and screw-retained implant prostheses (10.1\%) showed higher incidence of problems than internal implant-abutment connections and cement-retained implants, respectively. Screw loosening was most common in implant prostheses with single crowns (14.0\%).

Conclusion: Within the limits of the current study, we conclude that the incidence of screw loosening differs significantly according to the position of implant placement, the type of implant and manufacturer, implant diameter, the type of implant-abutment connection, the type of retention in the implant prosthesis, and the type of implant prosthesis.
\end{abstract}

Key words: Dental implants, Screw loosening, Regression analysis

[paper submitted 2019. 6. 23 / revised 2019. 10. 21 / accepted 2019. 11. 8]

\section{Yu-Lee Kim}

Department of Prosthodontics, Wonkwang University Dental Hospital, College of Dentistry, Wonkwang University, 895 Muwang-ro, Iksan 54538, Korea

TEL: +82-63-859-2938 FAX: +82-63-859-4002

E-mail:pro11@wku.ac.kr

ORCID: https://orcid.org/0000-0003-1350-5895

\section{Kyung-Hwan Kwon}

Department of Oral and Maxillofacial Surgery, Wonkwang University Dental Hospital, College of Dentistry, Wonkwang University, 895 Muwangro, Iksan 54538, Korea

TEL: +82-63-850-6486 FAX: +82-63-859-4002

E-mail:denhouse@naver.com

ORCID: https://orcid.org/0000-0002-5257-8440

*These authors contributed equally to this work as first authors.

These authors contributed equally to this work as co-corresponding authors.

(a) This is an open-access article distributed under the terms of the Creative Commons Attribution Non-Commercial License (http://creativecommons.org/ licenses/by-nc/4.0/), which permits unrestricted non-commercial use, distribution, and reproduction in any medium, provided the original work is properly cited. Copyright (C) 2020 The Korean Association of Oral and Maxillofacial Surgeons. All rights reserved.

\section{Introduction}

According to Brånemark ${ }^{1}$, since the concept of osseointegration was first introduced in dentistry, osseointegrated dental implants have been included in the treatment options for patients undergoing prosthodontic treatment. Dental implant treatment is suggested for edentulous patients. It has a high success rate, even after long periods of observation ${ }^{2,3}$.

Recently, many studies have reported problems following implant treatment. Goodacre et al. ${ }^{4}$ reported that potential complications of implant treatment include osseointegration failure, surgical complications, marginal bone loss, periimplantitis, mechanical complications, and aesthetic, masticatory, and phonetic problems. Calderon et al. ${ }^{5}$ stated that the most frequently observed problems after implant treatment were mechanical complications, including screw loosening, screw fractures, implant fractures, porcelain fractures, and retention loss of implant-retained overdentures.

Screw loosening is a commonly observed implant compli- 
cation $^{6-8}$. Jemt et al. ${ }^{6}$ found that screw loosening was the most common problem encountered during the first year in 107 single-implant restorations using the Brånemark system. For 5 years, Kreissl et al. ${ }^{7}$ observed partially edentulous patients who had undergone implant treatment and reported screw loosening in $6.7 \%$ of cases. Cho et al. ${ }^{8}$ observed 213 dental implant patients over a period of 3 to 7 years and reported that screw loosening occurred in $10.3 \%$ of single-implant restoration cases and $12.1 \%$ of multiple implant restorations.

The screw connects the implant to the abutment. When the screw is tightened, rotational force is applied to it, whereas tensile force develops as it is elongated. This tensile force gives rise to a clamping force that allows the implant-abutment connection to be maintained ${ }^{9}$. However, in the presence of a load greater than the clamping force or during a loss of preload, the screw can loosen ${ }^{10}$. When that happens, the abutment and implant become mobile, which can in turn affect the surrounding soft tissue and implant structure. Localized inflammation can occur, or a sinus tract can form. Furthermore, when the stress is concentrated, screw fractures, abutment fractures, or even implant fractures can occur ${ }^{11-13}$.

In this study, we used a retrospective analysis to determine the incidence and pattern of screw loosening in patients who received implants and identify factors that can increase the success rate of prosthodontic treatment.

\section{Materials and Methods}

\section{Patient selection}

We retrospectively reviewed the dental charts and radiographs of patients who received dental implant treatment at the Wonkwang University Dental Hospital Implant Center between January 2008 and October 2013 and completed their prosthetic rehabilitation.

This study was conducted after approval from the Institutional Review Board of Wonkwang University Dental Hospital (IRB No. WKDIRB201408-02).

We excluded patients who were missing information from their dental charts, whose implants were placed before the observation period even if they completed their prosthetic rehabilitation within the period of the study, and who suffered an implant failure after prosthetic rehabilitation. We also excluded patients who changed to a different type of implant prosthesis because of implant failure, those who underwent additional implant placement, and those who had a change in the type of opposing tooth.
After those exclusions, we analyzed 1,928 implants placed in 837 patients (448 males and 389 females; age range, 1993 years; mean age, 54.5 years). The post-loading follow-up period, i.e., the period from the time of implant placement to the end of December 2013, ranged from 0.25 to 70 months (mean period, 31.5 months).

\section{Types of implant and manufacturers}

Eight different types of implants were used from six manufacturers: ET (Dio, Busan, Korea), GSIII (Osstem, Seoul, Korea), TSIII (Osstem), USII (Osstem), Pitt-easy (Oraltronics, Bremen, Germany), Restore (Lifecore Biomedical, Chaska,

Table 1. Characteristics of the subjects and implants in this study

\begin{tabular}{|c|c|c|}
\hline & & $\begin{array}{l}\text { No. of patients } \\
\text { or implants }(\%)\end{array}$ \\
\hline \multirow[t]{2}{*}{ Sex } & Male & $448(53.5)$ \\
\hline & Female & $389(46.5)$ \\
\hline \multirow[t]{5}{*}{ Age (yr) } & $\leq 39$ & $104(12.4)$ \\
\hline & $40-49$ & $132(15.8)$ \\
\hline & $50-59$ & $319(38.1)$ \\
\hline & $60-69$ & $186(22.2)$ \\
\hline & $\geq 70$ & $96(11.5)$ \\
\hline \multirow{8}{*}{$\begin{array}{l}\text { Implants } \\
\text { (manufacturer) }\end{array}$} & ET (Dio) & $189(9.8)$ \\
\hline & GSIII (Osstem) & $11(0.6)$ \\
\hline & TSIII (Osstem) & $232(12.0)$ \\
\hline & USII (Osstem) & $356(18.5)$ \\
\hline & Pitt-easy (Oraltronics) & $94(4.9)$ \\
\hline & $\begin{array}{l}\text { Restore (Lifecore } \\
\text { Biomedical) }\end{array}$ & $4(0.2)$ \\
\hline & Osseotite (Biomet 3I) & 499 (25.9) \\
\hline & Xive (Friadent) & $543(28.2)$ \\
\hline \multirow[t]{4}{*}{ Implant diameter (mm) } & $\leq 3.5$ & $177(9.2)$ \\
\hline & $3.75-4.1$ & $1,009(52.3)$ \\
\hline & $4.5-4.9$ & $327(17.0)$ \\
\hline & $\geq 5$ & $415(21.5)$ \\
\hline \multirow[t]{4}{*}{ Implant length (mm) } & $\leq 9.5$ & $87(4.5)$ \\
\hline & $10-11.5$ & $1,269(65.8)$ \\
\hline & $12-14$ & $450(23.3)$ \\
\hline & $\geq 15$ & $122(6.3)$ \\
\hline \multirow[t]{2}{*}{ Arch } & Maxilla & $949(49.2)$ \\
\hline & Mandible & $979(50.8)$ \\
\hline \multirow[t]{3}{*}{ Position } & Anterior & $332(17.2)$ \\
\hline & Premolar & $423(21.9)$ \\
\hline & Molar & $1,173(60.8)$ \\
\hline \multirow{2}{*}{$\begin{array}{l}\text { Implant-abutment } \\
\text { connection type }\end{array}$} & Internal hex & $923(47.9)$ \\
\hline & External hex & $1,005(52.1)$ \\
\hline \multirow[t]{2}{*}{ Type of retention } & Cement & $1,063(55.1)$ \\
\hline & Screw & $865(44.9)$ \\
\hline \multirow[t]{4}{*}{ Type of prosthesis } & $\begin{array}{l}\text { Implant retained } \\
\text { overdenture }\end{array}$ & $32(1.7)$ \\
\hline & Splinted crown & $1,188(61.6)$ \\
\hline & Cantilever bridge & $17(0.9)$ \\
\hline & Single crown & $691(35.8)$ \\
\hline \multirow[t]{4}{*}{ Opposing tooth } & Denture & $61(3.2)$ \\
\hline & Fixed prosthesis & $380(19.7)$ \\
\hline & $\begin{array}{l}\text { Implant-supported } \\
\text { prosthesis }\end{array}$ & 358 (18.6) \\
\hline & Natural tooth & $1,129(58.6)$ \\
\hline
\end{tabular}

Ki-Young Lee et al: Clinical study on screw loosening in dental implant prostheses: a 6-year retrospective study. J Korean Assoc Oral Maxillofac Surg 2020 
MN, USA), Osseotite (Biomet 3I, Palm Beach Gardens, USA), and Xive (Friadent, Mannheim, Germany). All of those implants are root-form implants. The diameter of the implants ranged from $2.5-6 \mathrm{~mm}$, and the length ranged from 7-18 mm.(Table 1)

\section{Dental chart investigation}

When two or more implants were used in one patient and screw loosening occurred in individual implants, they were included as separate incidents in all categories except the sex and age of the patient. Additionally, we investigated cases of screw fractures, including whether the screw fracture occurred after screw loosening.

The characteristics of the subjects and implants used in this study have been summarized in Table 1 .

\section{Statistical analysis}

The association between each factor and screw loosening was analyzed using the chi-square test in the IBM SPSS Statistics (ver. 23.0; IBM, Armonk, NY, USA). Differences were considered significant when $P<0.05$.

A multivariate analysis was performed using binary logistic regression models to determine the predictive effect of the independent variables associated with screw loosening. The "enter" method, based on a level of significance of $P<0.10$, was used to incorporate variables into the models.

Table 2. Incidence of screw loosening and fracture

\begin{tabular}{cllc}
\hline & & & $\begin{array}{c}\text { No. of } \\
\text { implants (\%) }\end{array}$ \\
\hline $\begin{array}{c}\text { Screw } \\
\text { loosening }\end{array}$ & Incidence & No & $1,789(92.8)$ \\
& & Yes & $139(7.2)$ \\
& Frequency & Once & $108(77.7)$ \\
& & Twice & $20(14.4)$ \\
& & 3 times or more & $11(7.9)$ \\
Screw & Onset (months & $<6$ & $70(50.4)$ \\
fracture & Since loading) & $6-12$ & $29(20.9)$ \\
& & $12-24$ & $19(13.7)$ \\
& & $\geq 24$ & $21(15.1)$ \\
& Oncidence & No & $1,926(99.9)$ \\
& Onset (months & $<6$ & $2(0.1)$ \\
& Since loading) & $\geq 6$ & $1(50.0)$ \\
& Screw fracture after & No & $1(50.0)$ \\
& screw loosening & Yes & $1(50.0)$ \\
& & & $1(50.0)$ \\
\hline
\end{tabular}

Ki-Young Lee et al: Clinical study on screw loosening in dental implant prostheses: a 6-year retrospective study. J Korean Assoc Oral Maxillofac Surg 2020

\section{Results}

\section{Screw loosening and screw fracture in patients who} received implant treatment

Information about the incidence, frequency, and onset of screw loosening is provided in Table 2. Details about the incidence and onset of screw fractures and whether they occurred after screw loosening are also shown in Table 2.

\section{Relationship between screw loosening and the age and sex of the patient}

Although screw loosening occurred more frequently in males $(11.4 \%)$ than females $(8.0 \%)$, that difference was not statistically significant $(P>0.05)$.

Furthermore, although screw loosening was more frequently observed in patients older than 70 years (13.5\%) than in younger age groups, that association was also not statistically significant $(P>0.05)$. (Table 3$)$

\section{Relationship between screw loosening and the location of the implant}

The incidence of screw loosening was similar between the

Table 3. Screw loosening by sex and age

\begin{tabular}{llrrrr}
\hline & & \multicolumn{2}{c}{ Screw loosening } & \multirow{2}{*}{$\chi^{2}$} & \multirow{2}{*}{$P$-value } \\
\cline { 3 - 4 } & & No & Yes & & \\
\hline Sex & Male & $397(88.6)$ & $51(11.4)$ & 2.747 & 0.097 \\
& Female & $358(92.0)$ & $31(8.0)$ & & \\
Age (yr) & $\leq 39$ & $94(90.4)$ & $10(9.6)$ & 1.884 & 0.757 \\
& $40-49$ & $119(90.2)$ & $13(9.8)$ & & \\
& $50-59$ & $289(90.6)$ & $30(9.4)$ & & \\
& $60-69$ & $170(91.4)$ & $16(8.6)$ & & \\
& $\geq 70$ & $83(86.5)$ & $13(13.5)$ & & \\
\hline
\end{tabular}

Values are presented as number of patients $(\%)$.

Ki-Young Lee et al: Clinical study on screw loosening in dental implant prostheses: a 6-year retrospective study. J Korean Assoc Oral Maxillofac Surg 2020

Table 4. Screw loosening according to arch and position

\begin{tabular}{|c|c|c|c|c|c|}
\hline & \multicolumn{2}{|c|}{ Screw loosening } & \multirow{2}{*}{$\chi^{2}$} & \multirow{2}{*}{$P$-value } \\
\hline & & No & Yes & & \\
\hline \multirow[t]{2}{*}{ Arch } & Maxilla & $878(92.5)$ & $71(7.5)$ & 0.207 & 0.649 \\
\hline & Mandible & 911 (93.1) & $68(6.9)$ & & \\
\hline \multirow[t]{3}{*}{ Position } & Anterior & 309 (93.1) & $23(6.9)$ & 10.500 & $0.005^{*}$ \\
\hline & Premolar & 407 (96.2) & $16(3.8)$ & & \\
\hline & Molar & $1,073(91.5)$ & $100(8.5)$ & & \\
\hline
\end{tabular}

$* P<0.05$.

Values are presented as number of implants (\%).

Ki-Young Lee et al: Clinical study on screw loosening in dental implant prostheses: a 6-year retrospective study. J Korean Assoc Oral Maxillofac Surg 2020 
maxillary (7.5\%) and mandibular (6.9\%) arches, without any statistically significant difference $(P>0.05)$.

The position of the implant was classified as anterior, premolar, or molar. Screw loosening occurred most frequently in the molar region $(8.5 \%)$, followed by the anterior $(6.9 \%)$ and premolar regions $(3.8 \%)(P<0.05)$. (Table 4$)$

\section{Relationship between screw loosening and the type of implant and manufacturer}

The Pitt-easy implants showed the highest frequency of screw loosening (17.0\%), followed by the ET implants $(13.8 \%)$ and the Osseotite implants $(8.0 \%)(P<0.05)$.(Table 5)

\section{Relationship between screw loosening and implant diameter}

The diameters of the implants ranged from 2.5-6 mm. They varied by the type of implant and manufacturer, so we classified them into the following four groups: $\leq 3.5 \mathrm{~mm}, 3.75-4.1$ $\mathrm{mm}, 4.5-4.9 \mathrm{~mm}$, and $\geq 5 \mathrm{~mm}$. Screw loosening was observed most frequently in implants with a diameter $\geq 5 \mathrm{~mm}$ (incidence, $14.2 \%)(P<0.05)$. (Table 5)

\section{Relationship between screw loosening and implant length}

The lengths of the implants ranged from 7-18 $\mathrm{mm}$. The lengths also varied by the type of implant and manufacturer, so we classified them into the following four groups: $\leq 9.5$ $\mathrm{mm}, 10-11.5 \mathrm{~mm}, 12-14 \mathrm{~mm}$, and $\geq 15 \mathrm{~mm}$. The incidence of screw loosening was highest in implants with a length of 10-11.5 mm (7.9\%); however, that difference was not statistically significant $(P>0.05)$. (Table 5)

\section{Relationship between screw loosening and type of implant-abutment connection}

Implant-abutment connections are divided into external and internal types. Screw loosening was more frequent in the external group $(8.9 \%)$ than in the internal group $(5.4 \%)$ $(P<0.05)$. (Table 6)

Table 6. Screw loosening according to the implant-abutment connection type and implant prosthesis retention type

\begin{tabular}{|c|c|c|c|c|c|}
\hline & \multicolumn{2}{|c|}{ Screw loosening } & \multirow{2}{*}{$\chi^{2}$} & \multirow{2}{*}{$P$-value } \\
\hline & & No & Yes & & \\
\hline \multirow{2}{*}{$\begin{array}{l}\text { Implant- } \\
\text { abutment } \\
\text { connection } \\
\text { type }\end{array}$} & Internal hex & 873 (94.6) & $50(5.4)$ & \multirow[t]{2}{*}{8.504} & \multirow[t]{2}{*}{$0.004 *$} \\
\hline & External hex & 916 (91.1) & $89(8.9)$ & & \\
\hline \multirow{2}{*}{$\begin{array}{l}\text { Type of } \\
\text { retention }\end{array}$} & Cement & $1,011(95.1)$ & $52(4.9)$ & \multirow[t]{2}{*}{19.026} & \multirow[t]{2}{*}{$0.000 *$} \\
\hline & Screw & 778 (89.9) & 87 (10.1) & & \\
\hline
\end{tabular}

$* P<0.05$.

Values are presented as number of implants (\%).

Ki-Young Lee et al: Clinical study on screw loosening in dental implant prostheses: a 6-year retrospective study. J Korean Assoc Oral Maxillofac Surg 2020

Table 5. Screw loosening by the implants used in this study

\begin{tabular}{|c|c|c|c|c|c|}
\hline & & \multicolumn{2}{|c|}{ Screw loosening } & \multirow{2}{*}{$\chi^{2}$} & \multirow{2}{*}{$P$-value } \\
\hline & & No & Yes & & \\
\hline \multirow[t]{8}{*}{ Implants (manufacturer) } & ET (Dio) & $163(86.2)$ & $26(13.8)$ & 38.912 & $0.000 *$ \\
\hline & GSIII (Osstem) & $11(100)$ & $0(0)$ & & \\
\hline & TSIII (Osstem) & $225(97.0)$ & $7(3.0)$ & & \\
\hline & USII (Osstem) & $331(93.0)$ & $25(7.0)$ & & \\
\hline & Pitt-easy (Oraltronics) & $78(83.0)$ & $16(17.0)$ & & \\
\hline & Restore (Lifecore Biomedical) & $4(100)$ & $0(0)$ & & \\
\hline & Osseotite (Biomet 3I) & $459(92.0)$ & $40(8.0)$ & & \\
\hline & Xive (Friadent) & $518(95.4)$ & $25(4.6)$ & & \\
\hline \multirow[t]{4}{*}{ Implant diameter (mm) } & $\leq 3.5$ & $169(95.5)$ & $8(4.5)$ & 39.409 & $0.000 *$ \\
\hline & $3.75-4.1$ & $952(94.4)$ & $57(5.6)$ & & \\
\hline & $4.5-4.9$ & $312(95.4)$ & $15(4.6)$ & & \\
\hline & $\geq 5$ & $356(85.8)$ & $59(14.2)$ & & \\
\hline \multirow{4}{*}{ Implant length (mm) } & $\leq 9.5$ & $83(95.4)$ & $4(4.6)$ & 2.791 & 0.425 \\
\hline & $10-11.5$ & $1,169(92.1)$ & $100(7.9)$ & & \\
\hline & $12-14$ & $422(93.8)$ & $28(6.2)$ & & \\
\hline & $\geq 15$ & $115(94.3)$ & $7(5.7)$ & & \\
\hline
\end{tabular}

$* P<0.05$.

Values are presented as number of implants (\%).

Ki-Young Lee et al: Clinical study on screw loosening in dental implant prostheses: a 6-year retrospective study. J Korean Assoc Oral Maxillofac Surg 2020 
8. Relationship between screw loosening and the type of retention in the implant prosthesis

The retention used in the implant prosthesis is divided into screw-retained types and cement-retained types. Screw loosening was more common in screw-retained implants (10.1\%) than in cement-retained ones $(4.9 \%)(P<0.05)$.(Table 6$)$

\section{Relationship between screw loosening and the type of implant prosthesis}

Screw loosening was most common in single crowns (14.0\%), followed by cantilever bridges (11.8\%) and splinted crowns (3.4\%) $(P<0.05)$. (Table 7)

\section{Relationship between screw loosening and the type of opposing tooth}

Screw loosening was most frequently observed in cases with natural opposing teeth (7.9\%); however, that relationship was not statistically significant $(P>0.05)$. (Table 7)

\section{Repeated screw loosening}

The characteristics of the subjects and implants with more than one occurrence of screw loosening have been summarized in Table 8. Among the patients with more than one occurrence of screw loosening, $75.0 \%$ were males. Among the implant prostheses, $90.3 \%$ were single crowns. With respect to the type of opposing tooth, $77.4 \%$ had a natural tooth as the opposing tooth.
Table 8. Characteristics of the subjects and implants in this study with two or more incidents of screw loosening

\begin{tabular}{|c|c|c|}
\hline & & $\begin{array}{l}\text { No. of patients } \\
\text { or implants (\%) }\end{array}$ \\
\hline \multirow[t]{2}{*}{ Sex } & Male & $18(75.0)$ \\
\hline & Female & $6(25.0)$ \\
\hline \multirow[t]{5}{*}{ Age (yr) } & $\leq 39$ & $1(4.2)$ \\
\hline & $40-49$ & $5(20.8)$ \\
\hline & $50-59$ & $10(41.7)$ \\
\hline & $60-69$ & $6(25.0)$ \\
\hline & $\geq 70$ & $2(8.3)$ \\
\hline \multirow{8}{*}{$\begin{array}{l}\text { Implants } \\
\text { (manufacturer) }\end{array}$} & ET (Dio) & $10(32.3)$ \\
\hline & GSIII (Osstem) & $0(0)$ \\
\hline & TSIII (Osstem) & $0(0)$ \\
\hline & USII (Osstem) & $7(22.6)$ \\
\hline & Pitt-easy (Oraltronics) & $4(12.9)$ \\
\hline & $\begin{array}{l}\text { Restore (Lifecore } \\
\text { Biomedical) }\end{array}$ & $0(0)$ \\
\hline & Osseotite (Biomet 3I) & $8(25.8)$ \\
\hline & Xive (Friadent) & $2(6.5)$ \\
\hline \multirow{4}{*}{$\begin{array}{l}\text { Implant } \\
\text { diameter (mm) }\end{array}$} & $\leq 3.5$ & $0(0)$ \\
\hline & $3.75-4.1$ & $10(32.3)$ \\
\hline & $4.5-4.9$ & $2(6.5)$ \\
\hline & $\geq 5$ & $19(61.3)$ \\
\hline Implant & $\leq 9.5$ & $0(0)$ \\
\hline \multirow[t]{3}{*}{ length (mm) } & $10-11.5$ & $28(90.3)$ \\
\hline & $12-14$ & $3(9.7)$ \\
\hline & $\geq 15$ & $0(0)$ \\
\hline \multirow[t]{2}{*}{ Arch } & Maxilla & $16(51.6)$ \\
\hline & Mandible & $15(48.4)$ \\
\hline \multirow[t]{3}{*}{ Position } & Anterior & $1(3.2)$ \\
\hline & Premolar & $3(9.7)$ \\
\hline & Molar & $27(87.1)$ \\
\hline \multirow{2}{*}{$\begin{array}{l}\text { Implant-abutment } \\
\text { connection type }\end{array}$} & Internal hex & 7 (22.6) \\
\hline & External hex & $24(77.4)$ \\
\hline \multirow[t]{2}{*}{ Type of retention } & Cement & $6(19.4)$ \\
\hline & Screw & $25(80.6)$ \\
\hline \multirow[t]{4}{*}{ Type of prosthesis } & $\begin{array}{l}\text { Implant-retained } \\
\text { overdenture }\end{array}$ & $0(0)$ \\
\hline & Splinted crown & $3(9.7)$ \\
\hline & Cantilever bridge & $0(0)$ \\
\hline & Single crown & $28(90.3)$ \\
\hline \multirow[t]{4}{*}{ Opposing tooth } & Denture & $0(0)$ \\
\hline & Fixed prosthesis & $3(9.7)$ \\
\hline & $\begin{array}{l}\text { Implant-supported } \\
\text { prosthesis }\end{array}$ & $4(12.9)$ \\
\hline & Natural tooth & $24(77.4)$ \\
\hline
\end{tabular}

Ki-Young Lee et al: Clinical study on screw loosening in dental implant prostheses: a 6-year retrospective study. J Korean Assoc Oral Maxillofac Surg 2020

Table 7. Screw loosening according to implant prosthesis type and opposing teeth

\begin{tabular}{|c|c|c|c|c|c|}
\hline & & \multicolumn{2}{|c|}{ Screw loosening } & \multirow{2}{*}{$\chi^{2}$} & \multirow{2}{*}{$P$-value } \\
\hline & & No & Yes & & \\
\hline \multirow[t]{4}{*}{ Type of prosthesis } & Implant-retained overdenture & $32(100)$ & $0(0)$ & 77.392 & $0.000^{*}$ \\
\hline & Splinted crown & $1,148(96.6)$ & $40(3.4)$ & & \\
\hline & Cantilever bridge & $15(88.2)$ & $2(11.8)$ & & \\
\hline & Single crown & $594(86.0)$ & $97(14.0)$ & & \\
\hline \multirow{4}{*}{ Opposing tooth } & Denture & $61(100)$ & $0(0.0)$ & 6.325 & 0.097 \\
\hline & Fixed prosthesis & 357 (93.9) & $23(6.1)$ & & \\
\hline & Implant-supported prosthesis & $331(92.5)$ & $27(7.5)$ & & \\
\hline & Natural tooth & $1,040(92.1)$ & $89(7.9)$ & & \\
\hline
\end{tabular}

$* P<0.05$.

Values are presented as number of implants (\%).

Ki-Young Lee et al: Clinical study on screw loosening in dental implant prostheses: a 6-year retrospective study. J Korean Assoc Oral Maxillofac Surg 2020 


\section{Multiple regression analysis: binary regression model for screw loosening}

Variables that were statistically significant in the chi-square testing were used in the multivariate analysis: position, implant diameter, type of retention, and type of prosthesis. Table 9 displays the results of the final binary regression model for screw loosening in dental implants.

Implants placed in the anterior dentition had a 3.024 greater chance of screw loosening than implants placed in premolars. When the $\geq 5$-mm implant diameter group was taken as a reference, the $\leq 3.5 \mathrm{~mm}$ group had a 0.327 lower chance of screw loosening, and the 3.75-4.1 $\mathrm{mm}$ and 4.5$4.9 \mathrm{~mm}$ groups had 0.566 and 0.433 lower chances of screw loosening, respectively. Screw retention implants had a 1.581 greater chance of screw loosening than cement retention implants. Splinted crowns showed a 0.271 lower chance of screw loosening than single crowns.

\section{Discussion}

Jemt et al. ${ }^{6}$ reported that screw loosening occurred in $27.3 \%$ of 107 single-implant restorations placed in 92 patients. Kreissl et al. ${ }^{7}$ reported that $6.7 \%$ of 205 fixed-implant restorations placed in 76 patients experienced screw loosening, and Goodacre et al..$^{14}$ reported an overall screw-loosening incidence of $6.0 \%$.

In this study, screw loosening occurred in $7.2 \%$ of implants, usually once (77.7\%), followed by twice (14.4\%) and

Table 9. Final binary regression model for screw loosening in dental implants

\begin{tabular}{lcccc}
\hline \multicolumn{1}{c}{ Variable } & $\begin{array}{c}\text { Regression } \\
\text { coefficient }\end{array}$ & $P$-value & OR & CI for OR \\
\hline Constant & -2.173 & 0.000 & 0.114 & - \\
$\begin{array}{l}\text { Position } \\
\text { Anterior dentition }\end{array}$ & 1.107 & 0.003 & 3.024 & $1.455-6.287$ \\
$\quad$ Premolar dentition & - & - & 1 & - \\
Implant diameter (mm) & & & & \\
$\quad 3.5$ & -1.117 & 0.024 & 0.327 & $0.124-0.865$ \\
$\quad 3.75-4.1$ & -0.570 & 0.016 & 0.566 & $0.356-0.898$ \\
$\quad 4.5-4.9$ & -0.837 & 0.007 & 0.433 & $0.237-0.792$ \\
$\quad 5$ & - & - & 1 & - \\
Type of retention & & - & 1 & - \\
$\quad$ Cement & - & - & 1.581 & $1.037-2.409$ \\
$\quad$ Screw & 0.458 & 0.033 & & - \\
Type of prosthesis & & - & 1 & - \\
$\quad$ Single crown & - & - & 0.271 & $0.181-0.405$ \\
$\quad$ Splinted crown & -1.306 & 0.000 & 0.27 \\
\hline
\end{tabular}

(OR: odds ratio, CI: confidence interval)

$P=0.139$; Hosmer-Lemeshow test.

Ki-Young Lee et al: Clinical study on screw loosening in dental implant prostheses: a

6-year retrospective study. J Korean Assoc Oral Maxillofac Surg 2020 more than twice (7.9\%). Most cases happened within six months of loading (50.4\%), which is lower than the $53.5 \%$ of 43 implants reported by Cha et al. ${ }^{15}$ Within a year of loading, $71.3 \%$ of the screw loosening incidents we found had occurred, which exceeds the $67.0 \%$ reported by Kreissl et al. 7 . Similarly, when screw loosening occurred twice or more, $71.0 \%$ of incidents happened within six months after loading.

The incidence of screw loosening did not differ significantly according to sex. Duncan et al. ${ }^{16}$ conducted a 3-year retrospective study of 186 implants placed in 51 patients and reported a $9.4 \%$ incidence of screw loosening in males, which was much higher than they found in females (3.1\%). Lang et al. ${ }^{17}$ indicated that applying excessive loading on screws can dissipate the preload, resulting in screw loosening. Shinogaya et al. ${ }^{18}$ and Chladek et al. ${ }^{19}$ measured the occlusal force in each sex and reported a greater force in males; thus, it can be presumed that the difference in the occlusal force between the sexes leads to the difference in the incidence of screw loosening.

With respect to age, screw loosening was most common in the group older than 70 years (13.5\%), though the other groups showed a similar incidence $(P>0.05)$. In this study, patients older than 50 years made up $71.8 \%$ of the total patient population. In other words, it is likely that screw loosening is more frequent in elderly patients because tooth loss and implant treatment become more common as patients get older.

Screw loosening showed a similar incidence in the maxilla $(7.5 \%)$ and mandible $(6.9 \%)(P>0.05)$. Simon ${ }^{20}$ reported similar results (4.0\% in the maxilla and $3.2 \%$ in the mandible) in their 10-year retrospective study of patients who received implants. However, Jemt et al. ${ }^{6}$ reported a higher incidence of screw loosening in the maxilla (31.0\%) than in the mandible $(10.5 \%)$ in their 1-year retrospective study of single-implant restorations.

Screw loosening was most common in the molar region $(8.5 \%)$, followed by the anterior $(6.9 \%)$ and premolar regions $(3.8 \%)(P<0.05)$. The molar region showed a higher possibility of screw loosening because the occlusal force in the molar region is usually greater than that in the anterior region ${ }^{19}$. Cho et al. ${ }^{8}$ also reported a higher incidence of screw loosening in the molar region (12.3\%) than in the anterior region (7.7\%), and they also suggested greater occlusal force as the reason. They suggested that practitioners reduce excessive or off-axial loading on molar implants. Eckert and Wollan ${ }^{21}$ observed 1,170 implants in partially edentulous patients and reported differences in the incidence of screw loosening in the maxillary anterior, maxillary posterior, mandibular anterior, 
and mandibular posterior implants; nonetheless, they argued that the site of implant placement did not greatly affect screw loosening. In this study, $78.3 \%$ of screw loosening in the anterior region occurred in the maxilla. When the mandible moves forward, it is usually guided through the palatal surface of the maxillary anterior tooth, which applies off-axial loading to the implant and could increase the probability of screw loosening ${ }^{22}$. Even when implants are precisely manufactured, small differences can occur in the structure. In addition, the internal surface of the implant can have some rough parts that directly contact the thread of the screw. In a previous study, manufacturing flaws were mentioned as a suspected cause of screw loosening ${ }^{12}$. In addition, Al Jabbari et al. ${ }^{23}$ observed that screws from a single manufacturer, as well as those from different manufacturers, can differ in their shapes, microstructures, and microhardness. Those authors suggested that such differences could affect the preload. In fact, it is difficult to make a perfect adaptation for the internal surfaces of implants and screws; thus, there might be premature contact. When loading is applied to the implant, the premature contact surface wears off, which leads to settling, the amount of which depends on the initial roughness and amount of loading applied ${ }^{10,24}$. If a loss of preload occurs afterward, the possibility of screw loosening increases.

Regarding the diameter of the implant, screw loosening mostly occurred when the diameter was $\geq 5 \mathrm{~mm}(14.2 \%)$ $(P<0.05)$. Boggan et al. ${ }^{25}$ compared the static and fatigue strengths of the components in 4-mm and 5-mm diameter implants. They reported that the loading applied to the screw decreases as the diameter increases. Shin et al. ${ }^{26}$ measured the torque loss rate as they applied cyclic loading to an implant and reported that the torque loss rate was lower when the diameter of the implant was greater. Cho et al. ${ }^{8}$ showed a decreased incidence of screw loosening in wide-diameter implants $(5.8 \%)$ compared with standard-diameter implants $(14.5 \%)$, suggesting that a wider diameter is more favorable. On the other hand, we found screw loosening to occur most often in implants with diameters $\geq 5 \mathrm{~mm}$ in this study, unlike in previous studies. Fifty-nine implants showed screw loosening, 56 of which were placed in the molar region. Therefore, we suggest that the position of the implant has a greater effect on the incidence of screw loosening than the diameter of the implant.

In terms of implant length, screw loosening was most common in the $10-11.5 \mathrm{~mm}$ range $(7.9 \%)$. Although Urdaneta et $\mathrm{al}^{27}$ reported that an increase in the crown-to-implant length ratio can result in prosthetic complications - including screw loosening - we found a lower incidence in the $\leq 9.5 \mathrm{~mm}$ range $(4.6 \%)$ in our patient population.

As the types of implant-abutment connections relate to screw-loosening incidence, the external group showed higher incidence $(8.9 \%)$ than the internal group $(5.4 \%)(P<0.05)$. In an external implant-abutment connection - which consists of a butt-joint - micromovement of the crown is allowed. Moreover, the center of rotation is high, so it has a low resistance to lateral and rotational forces. These factors cause the high incidence of screw loosening. Furthermore, the weak connection of the implant-abutment interface acts as a fail-safe mechanism in cases of excessive loading ${ }^{28}$. To go beyond those limitations, internal implant-abutment connections with many different structures have been developed. The internal type protects the screw by deeply distributing the lateral force into the inner part of the implant. It also has a wide and solid contact surface. In addition, it lowers the possibility of screw loosening by resisting gap opening in the implant-abutment interface $^{29}$. Piermatti et al. ${ }^{30}$ and Tsuge and Hagiwara ${ }^{31}$ conducted screw-loosening experiments after the cyclic loading of external and internal connection implants. Contrary to our results, they reported no difference in torque loss between external and internal connection implants. Instead, they suggested that the material or form of the screw plays the most significant role in screw loosening.

The frequency of screw loosening was greater in screwretained implants $(10.1 \%)$ than in cement-retained implants $(4.9 \%)(P<0.05)$. The screw-retained type can easily become separated from the crown when it needs to be repaired, and because the passive fit of the implant superstructure is inferior to that in cement-retained implants, the possibility of screw loosening is increased ${ }^{32}$. Nissan et al. ${ }^{33}$ observed screwretained and cement-retained implants for 15 years and also reported a greater incidence of screw loosening in the screwretained type $(32 \% \pm 0.3 \%)$ than in the cement-retained type $(9 \% \pm 0.2 \%)$. As the misfit between the screw joint and the implant superstructure increases, the occurrence of complications such as screw loosening also increases. Cement-retained implants can protect the implant complex because the cement layer compensates for any misfit in the implant superstructure $^{34,35}$. Precautions are necessary because strain can occur in the bone around the implant while the crown is being cemented. Therefore, it is important to accomplish a passive fit in implant prostheses ${ }^{36}$.

Screw loosening was most common in single crowns (14.0\%), followed by cantilever bridges (11.8\%), and splinted crowns (3.4\%). Implant-retained overdentures did not show 
any screw loosening $(P<0.05)$. Jemt et al. ${ }^{6}$ reported that screw loosening is a frequent problem in single implants $(27.3 \%)$. Cho et al. ${ }^{8}$ reported that screw loosening occurred in $10.3 \%$ of single implants. Our results showed a high incidence of screw loosening in single implants as well. Balshi et al. ${ }^{37}$ suggested that screw loosening is common in single implants because the superstructure of the single implant in the molar region is usually bigger than the diameter of the implant, which allows the bending overload to be applied in every direction. In addition, the occlusal force is high. They also suggested that splinting adjacent dental implants lowers the incidence of screw loosening because the splinting removes the mesiodistal bending. In this study, most single implants were placed in the molar region (464 out of 691 single implants). Also, most screw loosening occurred in the molar area. A careful approach is thus required when placing an implant in the molar area, which exhibits a high prevalence of tooth loss and unfavorable biomechanical conditions. The cantilever structure can also increase the stress on an implant, so practitioners should avoid it, especially in a posterior partially edentulous segment ${ }^{38}$.

Haraldson and $\mathrm{Zarb}^{39}$ conducted research that compared the results from treating both jaws with an implant-supported fixed prosthesis with those from treating one jaw with an implant-supported prosthesis and leaving a natural or fixed partial denture on the opposing jaw. They reported that the former group had lower occlusal force. In our results, implantto-natural-tooth occlusions showed more screw loosening than implant-to-implant occlusions, though the result was not significant $(P>0.05)$. It is rational to assume that the relatively greater occlusal force of an implant-to-natural-tooth occlusion affected this finding. Likewise, occlusal interferencesuch as extrusion or wear of the natural teeth-can be an influencing factor, and failure to adjust for that during a prosthetic treatment to accommodate a patient's preference might affect screw loosening. On the other hand, Davis et al. ${ }^{40}$ reported that a fracture in the superstructure is more common in implants opposing implants than in those opposing natural teeth, but there was no difference in the screw loosening incidence between those two groups. They explained their finding by noting the lack of tactile sensitivity and proprioceptive feedback from implants.

Thirty-one implants in 24 patients showed screw loosening on two or more occasions, representing $22.3 \%$ of the all screw-loosening incidents. Once a screw is loosened, it is corrected by retightening or an occlusal adjustment. When screw loosening recurred in our population, a new screw or crown reproduction was placed, if necessary.

Two implants exhibited screw loosening a total of ten times. One was removed because of its mobility. It is unclear whether there is a relationship between screw loosening and osseointegration failure, but we assume that the stress accompanying screw loosening affected the implant-bone interface.

Bakaeen et al. ${ }^{41}$ evaluated the effect of implant diameter, restoration design, and the occlusal table on screw loosening in posterior single-tooth implants. They concluded that widediameter $(5 \mathrm{~mm})$ implants can cause a higher degree of screw loosening than conventional-diameter $(3.75 \mathrm{~mm})$ implants. This result matches our finding in this study. Bakaeen et al. ${ }^{41}$ suggested that narrowing the occlusal tables of restorations can reduce the degree of screw loosening.

Implants restored with single crowns have shown more screw loosening than multiple implants with multiple restored units $^{37}$. Our findings in this study are similar: splinted crowns had about 0.3 times less screw loosening than single crowns. To ease the incidence of screw loosening, it is advisable to maximize the joint clamping forces and curtail joint separating forces ${ }^{9}$. An article by Sadid-Zadeh et al. ${ }^{42}$ suggested torqueing the abutment or screw-retained crown with twice the force recommended by the manufacturer with an interval of 5 minutes between rotations.

The time of occurrence for screw loosening reported here might be somewhat inaccurate because not all patients visit for regular checkups, and some delay visiting because of personal circumstances despite an occurrence of screw loosening. The types of abutment and screws, materials used in the crown, and occlusal scheme were excluded from our classification criteria because such information is sometimes missing from dental charts.

In addition to the classification criteria used in this study, various other factors can affect screw loosening; therefore, long-term results should be sought in a prospective study. Moreover, an in-depth analysis of recurrent screw loosening is necessary in a future investigation.

\section{Conclusion}

The findings of our retrospective study, in which 1,928 implants were placed and loaded in 837 patients (448 males and 389 females), are as follows:

1. Screw loosening occurred in $7.2 \%$ of the cases. Of those, $22.3 \%$ showed repeated screw loosening.

2. Screw loosening normally occurred within six months of loading. 
3. With respect to the position of the implant placement, screw loosening was most frequently observed in the molar region.

4. Differences in the occurrence of screw loosening were observed among the different types of implants and manufacturers.

5. Screw loosening occurred most frequently in implants with a diameter $\geq 5 \mathrm{~mm}$.

6. External implant-abutment connections showed a higher incidence of screw loosening than internal implant-abutment connections.

7. A higher incidence of screw loosening was observed in screw-retained implant prostheses than in cement-retained implant prostheses.

8. Screw loosening was most frequently observed in single crowns, followed by cantilever bridges, splinted crowns, and implant-retained overdentures.

\section{ORCID}

Ki-Young Lee, https://orcid.org/0000-0001-6020-5815

Kyung Su Shin, https://orcid.org/0000-0002-5699-3414

Ji-Hye Jung, https://orcid.org/0000-0003-3322-4011

Hye-Won Cho, https://orcid.org/0000-0003-0623-5647

Kyung-Hwan Kwon, https://orcid.org/0000-0002-5257-8440

Yu-Lee Kim, https://orcid.org/0000-0003-1350-5895

\section{Authors' Contributions}

K.Y.L. participated in data collection and wrote the manuscript. K.Y.L. and K.S.S. participated in the study design and performed the statistical analysis. J.H.J., H.W.C., K.H.K., and Y.L.K. participated in the study design and coordination and helped to draft the manuscript. All authors read and approved the final manuscript.

\section{Ethics Approval and Consent to Participate}

This study was conducted after approval from the Institutional Review Board of Wonkwang University Dental Hospital (IRB No. WKDIRB201408-02), and the informed consent was waived.

\section{Conflict of Interest}

No potential conflict of interest relevant to this article was reported.

\section{References}

1. Brånemark PI. Osseointegration and its experimental background. J Prosthet Dent 1983;50:399-410.

2. Lekholm U, Gunne J, Henry P, Higuchi K, Lindén U, Bergström C, et al. Survival of the Brånemark implant in partially edentulous jaws: a 10-year prospective multicenter study. Int J Oral Maxillofac Implants 1999;14:639-45.

3. Adell R, Lekholm U, Rockler B, Brånemark PI. A 15-year study of osseointegrated implants in the treatment of the edentulous jaw. Int J Oral Surg 1981;10:387-416.

4. Goodacre CJ, Kan JY, Rungcharassaeng K. Clinical complications of osseointegrated implants. J Prosthet Dent 1999;81:537-52.

5. Calderon PS, Dantas PM, Montenegro SC, Carreiro AF, Oliveira AG, Dantas EM, et al. Technical complications with implantsupported dental prostheses. J Oral Sci 2014;56:179-84.

6. Jemt T, Laney WR, Harris D, Henry PJ, Krogh PH Jr, Polizzi G, et al. Osseointegrated implants for single tooth replacement: a 1-year report from a multicenter prospective study. Int J Oral Maxillofac Implants 1991;6:29-36.

7. Kreissl ME, Gerds T, Muche R, Heydecke G, Strub JR. Technical complications of implant-supported fixed partial dentures in partially edentulous cases after an average observation period of 5 years. Clin Oral Implants Res 2007;18:720-6.

8. Cho SC, Small PN, Elian N, Tarnow D. Screw loosening for standard and wide diameter implants in partially edentulous cases: 3 - to 7-year longitudinal data. Implant Dent 2004;13:245-50.

9. McGlumphy EA, Mendel DA, Holloway JA. Implant screw mechanics. Dent Clin North Am 1998;42:71-89.

10. Winkler S, Ring K, Ring JD, Boberick KG. Implant screw mechanics and the settling effect: overview. J Oral Implantol 2003;29:2425 .

11. Zarb GA, Schmitt A. The longitudinal clinical effectiveness of osseointegrated dental implants: the Toronto study. Part III: problems and complications encountered. J Prosthet Dent 1990;64:185-94.

12. Carlson B, Carlsson GE. Prosthodontic complications in osseointegrated dental implant treatment. Int J Oral Maxillofac Implants 1994;9:90-4.

13. Kim JM, Han JS, Lee SH, Yang JH, Lee JB, Kim YS. A study of screw loosening after dynamic continous fatigue test of several abutment screw. J Korean Acad Prosthodont 2003;41:519-31.

14. Goodacre CJ, Bernal G, Rungcharassaeng K, Kan JY. Clinical complications with implants and implant prostheses. J Prosthet Dent 2003;90:121-32.

15. Cha HS, Kim YS, Jeon JH, Lee JH. Cumulative survival rate and complication rates of single-tooth implant; focused on the coronal fracture of fixture in the internal connection implant. J Oral Rehabil 2013;40:595-602.

16. Duncan JP, Nazarova E, Vogiatzi T, Taylor TD. Prosthodontic complications in a prospective clinical trial of single-stage implants at 36 months. Int J Oral Maxillofac Implants 2003;18:561-5.

17. Lang LA, May KB, Wang RF. The effect of the use of a countertorque device on the abutment-implant complex. J Prosthet Dent 1999;81:411-7.

18. Shinogaya T, Bakke M, Thomsen CE, Vilmann A, Sodeyama A, Matsumoto M. Effects of ethnicity, gender and age on clenching force and load distribution. Clin Oral Investig 2001;5:63-8.

19. Chladek W, Lipski T, Karasiński A. Experimental evaluation of occlusal forces. Acta Bioeng Biomech 2001;3:25-37.

20. Simon RL. Single implant-supported molar and premolar crowns: a ten-year retrospective clinical report. J Prosthet Dent 2003;90:51721.

21. Eckert SE, Wollan PC. Retrospective review of 1170 endosseous implants placed in partially edentulous jaws. J Prosthet Dent 1998;79:415-21.

22. Papavasiliou G, Kamposiora P, Bayne SC, Felton DA. Three- 
dimensional finite element analysis of stress-distribution around single tooth implants as a function of bony support, prosthesis type, and loading during function. J Prosthet Dent 1996;76:633-40.

23. Al Jabbari YS, Fournelle R, Ziebert G, Toth J, Iacopino AM. Mechanical behavior and failure analysis of prosthetic retaining screws after long-term use in vivo. Part 1: characterization of adhesive wear and structure of retaining screws. J Prosthodont 2008;17:16880.

24. Siamos G, Winkler S, Boberick KG. Relationship between implant preload and screw loosening on implant-supported prostheses. J Oral Implantol 2002;28:67-73.

25. Boggan RS, Strong JT, Misch CE, Bidez MW. Influence of hex geometry and prosthetic table width on static and fatigue strength of dental implants. J Prosthet Dent 1999;82:436-40.

26. Shin HM, Huh JB, Yun MJ, Jeon YC, Chang BM, Jeong CM. Influence of the implant-abutment connection design and diameter on the screw joint stability. J Adv Prosthodont 2014;6:126-32.

27. Urdaneta RA, Rodriguez S, McNeil DC, Weed M, Chuang SK. The effect of increased crown-to-implant ratio on single-tooth lockingtaper implants. Int J Oral Maxillofac Implants 2010;25:729-43.

28. Maeda Y, Satoh T, Sogo M. In vitro differences of stress concentrations for internal and external hex implant-abutment connections: a short communication. J Oral Rehabil 2006;33:75-8.

29. Binon PP. Implants and components: entering the new millennium. Int J Oral Maxillofac Implants 2000;15:76-94.

30. Piermatti J, Yousef H, Luke A, Mahevich R, Weiner S. An in vitro analysis of implant screw torque loss with external hex and internal connection implant systems. Implant Dent 2006;15:427-35.

31. Tsuge T, Hagiwara Y. Influence of lateral-oblique cyclic loading on abutment screw loosening of internal and external hexagon implants. Dent Mater J 2009;28:373-81.

32. Michalakis KX, Hirayama H, Garefis PD. Cement-retained versus screw-retained implant restorations: a critical review. Int J Oral Maxillofac Implants 2003;18:719-28.

33. Nissan J, Narobai D, Gross O, Ghelfan O, Chaushu G. Long-term outcome of cemented versus screw-retained implant-supported partial restorations. Int J Oral Maxillofac Implants 2011;26:1102-7.

34. Binon PP. The effect of implant/abutment hexagonal misfit on screw joint stability. Int J Prosthodont 1996;9:149-60.

35. Pietrabissa R, Gionso L, Quaglini V, Di Martino E, Simion M. An in vitro study on compensation of mismatch of screw versus cement-retained implant supported fixed prostheses. Clin Oral Implants Res 2000;11:448-57.

36. Heckmann SM, Karl M, Wichmann MG, Winter W, Graef F, Taylor TD. Cement fixation and screw retention: parameters of passive fit. An in vitro study of three-unit implant-supported fixed partial dentures. Clin Oral Implants Res 2004;15:466-73.

37. Balshi TJ, Hernandez RE, Pryszlak MC, Rangert B. A comparative study of one implant versus two replacing a single molar. Int J Oral Maxillofac Implants 1996;11:372-8.

38. Rangert BR, Sullivan RM, Jemt TM. Load factor control for implants in the posterior partially edentulous segment. Int J Oral Maxillofac Implants 1997;12:360-70.

39. Haraldson T, Zarb G. A 10-year follow-up study of the masticatory system after treatment with osseointegrated implant bridges. Scand J Dent Res 1988;96:243-52.

40. Davis DM, Packer ME, Watson RM. Maintenance requirements of implant-supported fixed prostheses opposed by implant-supported fixed prostheses, natural teeth, or complete dentures: a 5-year retrospective study. Int J Prosthodont 2003;16:521-3.

41. Bakaeen LG, Winkler S, Neff PA. The effect of implant diameter, restoration design, and occlusal table variations on screw loosening of posterior single-tooth implant restorations. J Oral Implantol 2001;27:63-72.

42. Sadid-Zadeh R, Kutkut A, Kim H. Prosthetic failure in implant dentistry. Dent Clin North Am 2015;59:195-214.

How to cite this article: Lee KY, Shin KS, Jung JH, Cho HW, Kwon KH, Kim YL. Clinical study on screw loosening in dental implant prostheses: a 6-year retrospective study. J Korean Assoc

Oral Maxillofac Surg 2020;46:133-142. https://doi.org/10.5125/

jkaoms.2020.46.2.133 